Portland State University

PDXScholar

\title{
Factor Structure of the Short Form of the Barratt Impulsiveness Scale (BIS-15) in an Early Adolescent, Non-clinical Population
}

Phuc Toan Nguyen

Portland State University

Follow this and additional works at: https://pdxscholar.library.pdx.edu/honorstheses

Part of the Psychology Commons

Let us know how access to this document benefits you.

\section{Recommended Citation}

Nguyen, Phuc Toan, "Factor Structure of the Short Form of the Barratt Impulsiveness Scale (BIS-15) in an Early Adolescent, Non-clinical Population" (2020). University Honors Theses. Paper 906.

https://doi.org/10.15760/honors.927

This Thesis is brought to you for free and open access. It has been accepted for inclusion in University Honors Theses by an authorized administrator of PDXScholar. Please contact us if we can make this document more accessible: pdxscholar@pdx.edu. 
Factor structure of the short form of the Barratt Impulsiveness Scale (BIS-15) in an early adolescent, non-clinical population

by

Phuc Toan Nguyen

An undergraduate honors thesis submitted in partial fulfillment of the

requirements for the degree of

Bachelor of Science

in

University Honors, Public Health Education: Community Health Education and Psychology

Thesis Adviser

Dr. Lisa Marriott

Portland State University

2020 


\begin{abstract}
:
The Barratt Impulsiveness Scale (BIS) is a widely used tool for measuring impulsivity and has been influential in shaping current theories of impulse control. Studies have found that BIS factor structures can vary between different populations. The present study examined the factor structure of the widely used shortened form of BIS (BIS-15) within an early adolescent population. The BIS-15 has fifteen questions thought to assess three factors of impulsivity: nonplanning, motor, and attentional impulsivity. This study applied confirmatory factor analysis to a cross-sectional sample of 612 middle school students in grades six through eight. The published factor structure of the BIS-15 was not supported in the current study without modifications. The model fit was inadequate, and the structure suffered from discriminatory and convergent validity. Modifications to specific questions and future direction for the study were offered.
\end{abstract}




\section{Introduction}

Impulsivity is defined as "a predisposition toward rapid, unplanned reactions to internal or external stimuli without regard to the negative consequences of these reactions to the impulsive individuals or to others" (Moeller et al. 2001). High level of impulsivity is associated with various psychopathologies including substance use disorder, conduct disorder, delinquency, and certain attention-deficit/hyperactivity disorder (ADHD) subtypes (White et al., 1994; Luman et al., 2010; Robbins et al., 2012; Weafer et al., 2014; Lavender and Mitchell, 2015; Meule and Platte, 2015). In contrast, low level of impulsivity has been associated with compulsivity, obsessive compulsive disorder, and food-restricting types of anorexia nervosa (Fineberg et al., 2010; Dalley et al., 2011; Lavender et al., 2017). All individuals are expected to fall somewhere on the spectrum of impulsivity, even in the absence of clinical symptoms or diagnosis. Beyond clinical pathology, impulsivity may also affect daily health decision-making such as postponing exercise or choosing poor diet options (Sarmugam \& Worsley, 2015; Van Beurden et al., 2016; Kotbagi et al., 2017). Higher impulsivity is associated with lower science selfefficacy and reduced interest in STEM fields (Science, Technology, Engineering and Math; Marriott et al., 2019), suggesting adolescents' academic beliefs and interests may be influenced by non-clinical levels of impulsivity.

One of the most widely used self-report tools for assessing impulsivity is the Barratt Impulsiveness Scale (Stanford et al., 2009). The most recent version is the BIS-11, which includes 30 items (Patton et al., 1995). The BIS-15 was shortened from the BIS-11 and includes 15 items (Spinella, 2007). BIS-15 was identified to contain a three-factor structure, which represent as three different facets of impulsivity. These factors are non- 
planning impulsivity (lack of forethought), motor impulsivity (acting without thinking), and attentional impulsivity (inability to focus) (Spinella, 2007).

The three-factor structure of the BIS-15 was largely replicated in other languages and populations (Orozco-Cabal et al., 2010; Meule et al. 2011; Rousselle \& Vigneau, 2016; Bhat et al., 2018; Wang et al., 2019; Juneja et al., 2019; Meule et al., 2020). However, results are inconsistent as some items loaded onto different factors compared to the proposed structure. The BIS-15 has most largely been tested in both clinical and nonclinical population of young adults and adults. However, it has not been tested in adolescent population. This study tested the proposed BIS-15 factor structure in a large sample of middle school students. The model will be tested with three first-order latent factors which represents the subscale non-planning, motor, and attentional impulsivity).

\section{Methods}

\subsection{Participants}

This project was overseen by Oregon Health \& Science University’s (OHSU) Institutional Review Board (IRB, protocol \#3694) who approved the study. One middle school was recruited to participate in the current study based on a prior academic relationship with the investigator (L.K.M.) and schoolsociodemographics. The survey site was a suburban school located in the state of Washington. The site permitted use of their facilities, managed interaction with students, and oversaw parental opt-out forms that maintained student anonymity to study staff. The study's IRB protocol permitted the school to select an opt-in or opt-out procedure for parental notification, with the school selecting an opt-out procedure in this study. The school managed parental permissions to maintain student anonymity to OHSU study staff. The school selected which classes 
would administer surveys to support participation by all interested students. Selected teachers received an informational packet about the study, which included a teacher informational letter, student information sheets, student surveys, a data intake form, and a prepared paragraph to read to their students describing study goals, survey length, and voluntary participation in the anonymous research. Students were then given an information sheet about the study with time to ask questions. Students provided verbal assent to their teacher to participate and surveys included a printed introduction at the top of each survey reiterating procedures being voluntary and anonymous. One paper-based survey was administered to students. Completed surveys were returned to the teacher and immediately sealed in a manila envelope. Completed survey packets were returned to the main office to be mailed to the study team (postage pre-paid).

\subsection{Instrument}

A series of six different instruments were combined into a single survey. These instruments are as follow: Attention Deficit/Hyperactivity Disorder (ADHD) Self-Report Survey (18 items; Gray et al., 2014), impulsivity (BIS-15; 15 items; Spinella, 2007), Sources of Science Self-Efficacy (SSSE; 24 items; Chen \& Usher, 2013), mindset (20 items; Dweck, 2000), STEM interest (2-items; Tyler-Wood, 2010), Science SelfDetermination (SSD; 21 items; Deci et al., 2001), and Urgency, Premeditation, Perseverance, and Sensation Seeking (UPPS; 40 items; Tomko et al., 2016). For this study, only data from the BIS scale was analyzed. The English version of the BIS-15

(Spinella, 2007) was used for the current study (Table 3). The questionnaire comprised of 15 items with 5 items for each subscale (non-planning, motor, and attentional impulsivity). Items were measured on a four-point Likert scale (1- rarely/never, $2=$ 
occasionally, $3=$ often, $4=$ almost always/always). Total score ranges from 15-60. Higher score on this scale means more impulsivity. Six items (question 6, 7, 8, 9, 10 and 13) were reverse scored as previously reported (Spinella, 2007).

\subsection{Data analysis}

Internal consistency, which describes the level of correlation between different item of the same questionnaire, was calculated using Cronbach's alpha reliability coefficient (Kline, 2015). The consistency of the items was interpreted as $\alpha<0.6$ (unacceptable), $\alpha=0.6-0.65$ (undesirable), $\alpha=0.65-0.70$ (minimally acceptable), $\alpha=0.70-0.80$ (respectable), $\alpha=0.80-0.90$ (excellent), and $\alpha>0.9$ (excessive consistency) based on previously reported guidelines (Peterson, 1994).

Confirmatory factor analysis was conducted using the structural equation modeling module of Statistical Package for the Social Sciences (SPSS) Analysis of Moment Structure (AMOS; IBM; version 25) (source of this - e.g., Petaluma, CA). The model was specified to have three first-order latent factors (with each factor consist of five items; Spinella, 2007). Model fit was evaluated using the model Chi-Square, the Comparative Fit Index (CFI), Root Mean Square Residual (SRMR), and Root Mean Square Error of Approximation (RMSEA) as recommended (Kline, 2015). CFI recommended cutoff value is $\geq .95$ with value of 1 indicating a perfect fit. SRMR and RMSEA recommended cutoff values are $\leq .08$ with 0 indicating perfect fit. At minimum, factor loadings for items should be $>0.32$ (Tabachnick \& Fidell, 2012), $\geq 0.4$ preferred (Santor et al., 2011), and $\geq 0.5$ indicating solid factor loading (Costello \& Osborne, 2015). Testing of the Composite Reliability (CR), Average Variance Extraction (AVE), and Maximum Shared Variance (MSV) were conducted in the confirmatory factor analysis to 
further examine the construct validity based on recommendation of Hair et al. (2010), with $\mathrm{CR}$ values $>0.7$ indicating good measurement reliability. AVE values $>0.5$ indicates that the measurement has no convergent validity. When MSV is less than AVE, there is no discriminant validity (Hair et al., 2010).

\section{Results}

\subsection{Participants}

A total of $n=612$ middle school students from grade 6 to 8 enrolled at the survey site (NCES 2017) and were administered the survey. For this analysis, all missing cases were taken out, reducing the participants to $n=463$ (missing data $=149$ ). Out of the 149 missing data, 87 participants did not started the BIS-15 questionnaire and 62 participants started but did not finish the questionnaire. The sample's gender was $43.4 \%$ male, $50.3 \%$ female, $2.6 \%$ non-binary or other, and $3.9 \%$ prefer not to say. The mean age of participants was 13.84 years old with standard deviation of 1.12 years.

\subsection{Descriptive statistics}

Total impulsivity scores were distributed across a wide range for the BIS-15. Statistical tests indicate scores were not normally distributed on the $S-K$ test $(p=0.005)$. The skewness is .291 indicating a slight positive skew.

\subsection{Construct validity}

No metrics met the cut off recommended for model fit $(p>0.05$; RMSEA $\leq .08$; SRMR $\leq .08 ; \mathrm{CFI} \geq .90 ;$ table 1$) \cdot \chi^{2}$-test was significant $\left(\chi^{2}(87)=561,928, p<.001\right)$, indicating that the model did not fit. However, it is expected since Chi-Square test is influenced by large sample size (Hooper et al., 2008).Overall, this result suggested that the data does 
not fit the current three-factor structured originally proposed (Spinella, 2007).

Standardized factor loadings are displayed in table 2. Of the 15 items in the scale, 12 $(80 \%)$ of the items exceeded $0.5,2(13 \%)$ of the items exceeded 0.32 , and $1(7 \%)$ was below .32. Between the three subscales, attentional and motor are the most correlated at .747 (table 3). Instruments' total scores showed respectable internal consistency with Cronbach's alpha coefficients $(\alpha=0.756)$. However, the CR for latent factor “motor” was less than the recommended cut off, which is $>0.5$ (Table 4). Both AVE and MSV for motor and attentional latent factors did not meet the recommended cut off value (AVE > 0.5, MSV < AVE; table 4). It showed that both factors suffered from discriminate and convergent validity issues. For latent factor Non-planning, only AVE did not meet the cut off value (table 4) indicating that the factor suffered from convergent validity issue. This indicates that there is reliability issue for the Motor latent factor.

Table 1. Confirmatory factor analysis goodness of fit indices for BIS-15

\begin{tabular}{|l|c|c|}
\hline \multicolumn{1}{|c|}{ Goodness of fit statistics } & $\begin{array}{c}\text { Recommended cut offs } \\
\text { (Kline, 2015) }\end{array}$ & BIS-15 \\
\hline Chi-square p value & $>0.05$ & .000 \\
\hline CFI & $\geq .90$ & .754 \\
\hline RMSEA & $\leq .08$ & .109 \\
\hline SRMR & $\leq .08$ & .099 \\
\hline
\end{tabular}


Table 2. Standardized factor loadings of the BIS-15 model with three first-order impulsivity factors

\begin{tabular}{|l|c|c|c|}
\hline Items & Factor & Scored & $\begin{array}{c}\text { Factor } \\
\text { loading }\end{array}$ \\
\hline 1. I act on impulse. & Motor & + & .53 \\
\hline 2. I act on the spur of the moment. & Motor & + & .51 \\
\hline 3. I do things without thinking. & Motor & + & .80 \\
\hline 4. I say things without thinking. & Motor & + & .75 \\
\hline 5. I buy things on impulse. & Motor & + & .43 \\
\hline 6. I plan for job security. & Non-Planning & $\mathrm{RS}$ & .31 \\
\hline 7. I plan for the future. & Non-Planning & $\mathrm{RS}$ & .52 \\
\hline 8. I save regularly. & Non-Planning & $\mathrm{RS}$ & .57 \\
\hline 9. I plan tasks carefully. & Non-Planning & $\mathrm{RS}$ & .86 \\
\hline 10. I am a careful thinker & Non-Planning & $\mathrm{RS}$ & .66 \\
\hline 11. I am restless at lectures or talks & Attentional & + & .56 \\
\hline 12. I squirm at plays or lectures & Attentional & + & .64 \\
\hline 13. I concentrate easily & Attentional & $\mathrm{RS}$ & .36 \\
\hline 14. I don't pay attention & Attentional & + & .63 \\
\hline 15. I am easily bored solving thought problems & Attentional & + & .54 \\
\hline
\end{tabular}

*Items reverse scored are denoted by 'RS' (reverse scored) whereas '+' denotes items positively scored. 
Table 3. Correlation between the factors between BIS-15 subscale

\begin{tabular}{|l|c|c|c|}
\hline & Motor & Non-Planning & Attentional \\
\hline Motor & - & .121 & .747 \\
\hline Non-Planning & .121 & - & .279 \\
\hline Attentional & .747 & .279 & - \\
\hline
\end{tabular}

Table 4. Composite Reliability (CR), Average Variance Extraction (AVE), and Maximum Shared Variance (MSV) for the latent factors.

\begin{tabular}{|l|r|r|r|}
\hline & \multicolumn{1}{l|}{ CR } & \multicolumn{1}{l|}{ AVE } & \multicolumn{1}{l|}{ MSV } \\
\hline Attention & 0.681 & 0.307 & 0.558 \\
\hline Motor & 0.748 & 0.386 & 0.558 \\
\hline Non-Planning & 0.733 & 0.375 & 0.078 \\
\hline
\end{tabular}

$*$ CR values $>0.7$ indicating good measurement reliability. AVE values $>0.5$ indicates that the measurement has no convergent validity. When MSV is less than AVE, there is no discriminant validity (Hair et al., 2010).

\section{Discussion}

The overarching goal of this research was to test the three-factor structure of BIS-15.

Such exploration of latent structure can inform theory and is important in interpreting the original proposed structure of the instrument. In the following sections, we will consider 
the result of this assessment, their impact on the proposed structure, and future steps for modification.

\subsection{Result assessment}

The BIS-15 is a shorter version of the original questionnaire, BIS-11 (15 items vs 30 items). Confirmatory factor analysis was used to examine the BIS-15 three-factor structures proposed by Spinella (2007). The results in the present study provided no support for the theory that BIS-15 can be divided into three subscales, each with five questions, for an early adolescent, non-clinical population. Despite the scale showing good internal reliability through Cronbach's alpha, its data did not fit into the model through model fit confirmatory factor analysis and one of its factors did not meet the CR reliability test. The low value of $\mathrm{CR}=0.681$ not meeting the recommended cut off $(\mathrm{CR}$ $>0.7$; Hair et al., 2010) indicates that some items measured the factor "motor" inadequately, potentially incorrectly and needed revision. The measurement seemed to suffer from convergent validity based on the low AVE values not meeting the cut off on all three latent factors. The issue potentially stemmed from low factor loading of question 5, 6, and 13 (table 2). Finally, the high MSV value for factor "motor" and "attentional" indicated that they suffered from discriminatory validity. This indicates that some items cross-loaded to another factor. Overall, the model will need modifications to better serve this population.

\subsection{Proposed modifications}

Exploratory factor analysis (EFA) will need to be conducted to address the current discriminatory validity issue. By performing EFA, a more detailed pattern matrix of all item loadings will be displayed and help identify cross loading items. Once these items 
are identified, a closer look at the wording and the original theory will help guide the changes, as these constructs are heavily influenced and shaped by their associated theory. The same process will also be done for items with low factor loading to address the convergent validity issue. As low loading denotes that the factor is not explained by the items well enough. For this population, the problem might stem from the wording of the items. For example, both item 5 (I buy things on impulse) and 6 (I plan for job security) are not as relevant for middle school students. Middle school students will most likely not have enough money to buy things whenever or think about the availability and retention rate of their future jobs. These items need to be reworded to better reflect this population. However, question 13 (I concentrate easily) does not seem to have the same wording problem. Question 13 will need the EFA pattern matrix to identify its low factor loading. 


\section{References}

Bhat, N. A., Roopesh, B. N., Bhaskarapillai, B., \& Benegal, V. (2018). Validation of the Barratt Impulsiveness Scale- short form among Indian adolescents. Asian Journal of Psychiatry, 37, 172-177. https://doi.org/10.1016/j.ajp.2018.10.009

Chen, J. A., \& Usher, E. L. (2013). Profiles of the sources of science self-efficacy. Learning and Individual Differences, 24, 11-21. https://doi.org/10.1016/j.lindif.2012.11.002

Costello, A. B., \& Osborne, J. (2005). Best practices in exploratory factor analysis: Four recommendations for getting the most from your analysis. Exploratory Factor Analysis, 10(7), 10.

Dalley, J. W., Everitt, B. J., \& Robbins, T. W. (2011). Impulsivity, compulsivity, and top-down cognitive control. Neuron, 69(4), 680-694. https://doi.org/10.1016/j.neuron.2011.01.020

Deci, E. L., Ryan, R. M., Gagné, M., Leone, D. R., Usunov, J., \& Kornazheva, B. P. (2001). Need Satisfaction, Motivation, and Well-Being in the Work Organizations of a Former Eastern Bloc Country: A Cross-Cultural Study of Self-Determination. Personality and Social Psychology Bulletin, 27(8), 930-942. https://doi.org/10.1177/0146167201278002

Dweck, C. S. (2000). Self-theories: Their Role in Motivation, Personality, and Development. Psychology Press.

Fineberg, N. A., Potenza, M. N., Chamberlain, S. R., Berlin, H. A., Menzies, L., Bechara, A., Sahakian, B. J., Robbins, T. W., Bullmore, E. T., \& Hollander, E. (2010). Probing Compulsive and Impulsive Behaviors, from Animal Models to Endophenotypes: A Narrative Review. Neuropsychopharmacology, 35(3), 591-604. https://doi.org/10.1038/npp.2009.185 
Gray, S., Woltering, S., Mawjee, K., \& Tannock, R. (2014). The Adult ADHD Self-Report Scale (ASRS): Utility in college students with attention-deficit/hyperactivity disorder. PeerJ, 2, e324. https://doi.org/10.7717/peerj.324

Hair, J., Black, W., Babin, B., and Anderson, R. (2010). Multivariate data analysis (7th ed.): Prentice-Hall, Inc. Upper Saddle River, NJ, USA.

Hooper, D., Coughlan, J., \& Mullen, M. (2007). Structural Equation Modeling: Guidelines for Determining Model Fit. The Electronic Journal of Business Research Methods, 6.

Juneja, R., Chaiwong, W., Siripool, P., Mahapol, K., Wiriya, T., Shannon, J. S., Petchkrua, W., Kunanusont, C., \& Marriott, L. K. (2019). Thai adaptation and reliability of three versions of the Barratt Impulsiveness Scale (BIS 11, BIS-15, and BIS-Brief). Psychiatry Research, 272, 744-755. https://doi.org/10.1016/j.psychres.2018.12.173

Kline, R. B. (2015). Principles and Practice of Structural Equation Modeling, Fourth Edition. Guilford Publications.

Kotbagi, G., Morvan, Y., Romo, L., \& Kern, L. (2017). Which dimensions of impulsivity are related to problematic practice of physical exercise? Journal of Behavioral Addictions, 6(2), 221-228. https://doi.org/10.1556/2006.6.2017.024

Lavender, J. M., \& Mitchell, J. E. (2015). Eating Disorders and Their Relationship to Impulsivity. Current Treatment Options in Psychiatry, 2(4), 394-401. https://doi.org/10.1007/s40501-015-0061-6

Lavender, J. M., Goodman, E. L., Culbert, K. M., Wonderlich, S. A., Crosby, R. D., Engel, S. G., Mitchell, J. E., Le Grange, D., Crow, S. J., \& Peterson, C. B. (2017). Facets of Impulsivity and Compulsivity in Women with Anorexia Nervosa. European Eating 
Disorders Review: The Journal of the Eating Disorders Association, 25(4), 309-313. https://doi.org/10.1002/erv.2516

Luman, M., Tripp, G., \& Scheres, A. (2010). Identifying the neurobiology of altered reinforcement sensitivity in ADHD: A review and research agenda. Neuroscience and Biobehavioral Reviews, 34(5), 744-754. https://doi.org/10.1016/j.neubiorev.2009.11.021

Marriott, L. K., Coppola, L. A., Mitchell, S. H., Bouwma-Gearhart, J. L., Chen, Z., Shifrer, D., Feryn, A. B., \& Shannon, J. (2019). Opposing effects of impulsivity and mindset on sources of science self-efficacy and STEM interest in adolescents. PLoS ONE, 14(8). https://doi.org/10.1371/journal.pone.0201939

Meule, A., \& Platte, P. (2015). Facets of impulsivity interactively predict body fat and binge eating in young women. Appetite, 87, 352-357. https://doi.org/10.1016/j.appet.2015.01.003

Meule, A., Vögele, C., \& Kübler, A. (2011). Psychometrische evaluation der deutschen barratt impulsiveness scale - kurzversion (BIS-15). [Psychometric evaluation of the German Barratt Impulsiveness Scale - Short Version (BIS-15).]. Diagnostica, 57(3), 126-133. https://doi.org/10.1026/0012-1924/a000042

Moeller, F. G., Barratt, E. S., Dougherty, D. M., Schmitz, J. M., \& Swann, A. C. (2001). Psychiatric aspects of impulsivity. The American Journal of Psychiatry, 158(11), 17831793. https://doi.org/10.1176/appi.ajp.158.11.1783

Orozco-Cabal, L., Rodríguez, M., Herin, D. V., Gempeler, J., \& Uribe, M. (2010). Validity and Reliability of the Abbreviated Barratt Impulsiveness Scale in Spanish (BIS-15S). Revista 
Colombiana De Psiquiatria, 39(1), 93-109. https://doi.org/10.1016/s0034$\underline{7450(14) 60239-0}$

Patton, J. H., Stanford, M. S., \& Barratt, E. S. (1995). Factor structure of the Barratt impulsiveness scale. Journal of Clinical Psychology, 51(6), 768-774. https://doi.org/10.1002/1097-4679(199511)51:6<768::aid-jclp2270510607>3.0.co;2-1

Peterson, R. A. (1994). A Meta-analysis of Cronbach's Coefficient Alpha. Journal of Consumer Research, 21(2), 381-391. https://doi.org/10.1086/209405

Robbins, T. W., Gillan, C. M., Smith, D. G., de Wit, S., \& Ersche, K. D. (2012). Neurocognitive endophenotypes of impulsivity and compulsivity: Towards dimensional psychiatry. Trends in Cognitive Sciences, 16(1), 81-91. https://doi.org/10.1016/j.tics.2011.11.009

Rousselle, P., \& Vigneau, F. (2016). Adaptation et validation d'une version brève en langue française du questionnaire d'impulsivité de Barratt (BIS-15). Revue Européenne de Psychologie Appliquée/European Review of Applied Psychology. https://doi.org/10.1016/j.erap.2016.05.001

Santor, D. A., Haggerty, J. L., Lévesque, J.-F., Burge, F., Beaulieu, M.-D., Gass, D., \& Pineault, R. (2011). An Overview of Confirmatory Factor Analysis and Item Response Analysis Applied to Instruments to Evaluate Primary Healthcare. Healthcare Policy, 7(Spec Issue), 79-92.

Sarmugam, R., \& Worsley, A. (2015). Dietary Behaviours, Impulsivity and Food Involvement: Identification of Three Consumer Segments. Nutrients, 7(9), 8036-8057. https://doi.org/10.3390/nu7095379 
Spinella, M. (2007). Normative Data and a Short Form of the Barratt Impulsiveness Scale. International Journal of Neuroscience, 117(3), 359-368. https://doi.org/10.1080/00207450600588881

Stanford, M. S., Mathias, C. W., Dougherty, D. M., Lake, S. L., Anderson, N. E., \& Patton, J. H. (2009). Fifty years of the Barratt Impulsiveness Scale: An update and review. Personality and Individual Differences, 47(5), 385-395. https://doi.org/10.1016/j.paid.2009.04.008

Tabachnick, B. G., Fidell, L. S., \& Ullman, J. B. (2019). Using multivariate statistics (Seventh edition). Pearson.

Tomko, R. L., Prisciandaro, J. J., Falls, S. K., \& Magid, V. (2016). The structure of the UPPS-RChild impulsivity scale and its relations with substance use outcomes among treatmentseeking adolescents. Drug and Alcohol Dependence, 161, 276-283. https://doi.org/10.1016/j.drugalcdep.2016.02.010

Tyler-Wood, T., Knezek, G., \& Christensen, R. (2010). Instruments for Assessing Interest in STEM Content and Careers Journal of Technology and Teacher Education. 18(2), 341363.

van Beurden, S. B., Greaves, C. J., Smith, J. R., \& Abraham, C. (2016). Techniques for modifying impulsive processes associated with unhealthy eating: A systematic review. Health Psychology: Official Journal of the Division of Health Psychology, American Psychological Association, 35(8), 793-806. https://doi.org/10.1037/hea0000337

Wang, M.-C., Deng, Q., Shou, Y., Lai, H., Deng, J., Gao, Y., \& Li, Z. (2019). Assessing Impulsivity in Chinese: Elaborating Validity of BIS Among Male Prisoners. Criminal Justice and Behavior, 46(3), 492-506. https://doi.org/10.1177/0093854818806033 
Weafer, J., Mitchell, S. H., \& de Wit, H. (2014). Recent Translational Findings on Impulsivity in Relation to Drug Abuse. Current Addiction Reports, 1(4), 289-300. https://doi.org/10.1007/s40429-014-0035-6

White, J. L., Moffitt, T. E., Caspi, A., Bartusch, D. J., Needles, D. J., \& Stouthamer-Loeber, M. (1994). Measuring impulsivity and examining its relationship to delinquency. Journal of Abnormal Psychology, 103(2), 192-205. https://doi.org/10.1037//0021-843x.103.2.192 